\title{
PENURUNAN KADAR EMISI GAS BUANG KARBON MONOKSIDA (CO) DENGAN PENAMBAHAN ARANG AKTIF PADA KENDARAAN BERMOTOR DI YOGYAKARTA
}

\author{
Dicky Maryanto, Surahma Asti Mulasari, Dyah Suryani \\ Fakultas Kesehatan Masyarakat, Universitas Ahmad Dahlan, Yogyakarta
}

\begin{abstract}
Background: Growth of motor vehicle in Yogyakarta mean 11,9 percent of year. A new motor vehicle Accretion every year reach 83.761 unit, more than 90 percent among other things vehicle wheel two or motorbike. In line with increase sum up the motor vehicle cause the increase sum up the consumption oil fuel, so that cause the gas throw away the motor vehicle like Carbon Monoxide ( CO), Hydrocarbon ( $\mathrm{HC}$ ), Oxide Nitrogen ( Nox), Oxide Sulfur (Sox) And partikulat Pb mount also. Excelsior of concentration $\mathrm{CO}$ which breathed by human being hence fatal progressively risk accepted by the human being, even cause the death. Nature of not scentless gaseous $\mathrm{CO}$ and not chromatic also very the toxic, then $\mathrm{CO}$ is often conceived of silent killer. Strive the operation with the modification of burner machine conduct the innovation of muffler. With the addition of glass wool, active charcoal, water or other dissimilar substance having the character of adsorb or absorb. this Research target to Know the degradation of rate of gas emission throw away the carbon monoxide ( $\mathrm{CO}$ ) with the active charcoal addition a motor vehicle.

Method: this was experimentant research by one group pre and post design descriptively and analytic. Sample of research some of gas emission throw away the carbon monoxide (CO) high secretory the muffler of motorcycle honda supra, measuring instrument used in this research field observation with the active charcoal addition muffler motorcycle, and measuring instrument of inspection of carbon monoxide rate (CO) By analysis means of Auto Check 974/S. Analysis the data use the one way Anova.

Result : test of Anova of degradation of rate of gas emission throw away the carbon monoxide ( CO) with the active charcoal addition 50,100, 150 gram of motor vehicle. Assess the mean difference average the rate $150 \mathrm{gr}$ to rate $50 \mathrm{gr}$ showing number $-1.17600^{*}$ meaning active charcoal gift $150 \mathrm{gr}$ better the than gift $50 \mathrm{gr}$. Seen from value sig for the line of fifth assess sig 0,035<0,05 meaning Ho refused and $\mathrm{Ha}$ accepted so that there degradation difference by sig.

Conclusion : There was degradation of rate of gas emission throw away the carbon monoxide ( $\mathrm{CO}$ ) with the active charcoal addition at motor vehicle.
\end{abstract}

Keywords : Carbon Monoxide ( CO), Active Charcoal Gift.

\section{PENDAHULUAN}

Di Indonesia kendaraan bermotor meningkat jumlahnya dari tahun ke tahun, gas buang yang di timbulkan dari kendaraan bermotor tersebut menimbulkan polusi udara sebesar 70 sampai 80 persen, sedangkan pencemaran udara akibat industri hanya 20-30 persen saja. Banyak polusi udara terjadi di mana-mana yang disebabkan oleh banyak hal antara lain : asap kendaraan, asap pabrik, pembakaran sampah dan sebagainya. Asap kendaraan merupakan penyebab terbesar terjadinya polusi udara karena perkembangan teknologi pada berbagai bidang khususnya di bidang transportasi dewasa ini, mengakibatkan jumlah kendaraan bermotor dengan berbagai jenis dan merk meningkat cukup tinggi. Peningkatan jumlah kendaraan bermotor yang ada disebabkan semakin tingginya aktivitas masyarakat yang sangat membutuhkan sarana transportasi untuk kelancaran aktivitas mereka. ${ }^{1}$

Karbon monoksida yang keluar dari knalpot akan berada di udara ambient, jika terhirup oleh manusia maka molekul tersebut akan masuk kedalam saluran 
pernapasan terus masuk ke dalam paru - paru dan kemudian akan menempel pada haemoglobin darah membentuk carboxy Haemoglobin $(\mathrm{COHb}){ }^{2}$

Semakin tinggi konsentrasi $\mathrm{CO}$ yang terhirup oleh manusia maka semakin fatal resiko yang diterima oleh manusia tersebut, bahkan dapat menyebabkan kematian. Sifat $\mathrm{CO}$ yang berupa gas yang tidak berbau dan tidak berwarna serta sangat toksik tersebut, maka CO sering disebut sebagai silent killer. Efek terhadap kesehatan gas $\mathrm{CO}$ merupakan gas yang berbahaya untuk tubuh karena daya ikat gas $\mathrm{CO}$ terhadap $\mathrm{Hb}$ adalah 240 kali dari daya ikat $\mathrm{CO}$ terhadap O2. Apabila gas $\mathrm{CO}$ darah ( $\mathrm{HbCO})$ cukup tinggi, maka akan mulai terjadi gejala antara lain pusing kepala (HbCO 10 persen), mual dan sesak nafas ( $\mathrm{HbCO} 20$ persen), gangguan penglihatan dan konsentrasi menurun ( $\mathrm{HbCO} 30$ persen) tidak sadar, koma (HbCO 40-50 persen) dan apabila berlanjut akan dapat menyebabkan kematian. Pada paparan menahun akan menunjukkan gejala gangguan syaraf, infark otak, infark jantung dan kematian bayi dalam kandungan. Gas CO yang tinggi di dalam darah dapat berasal dari rokok dan asap dari kendaraan bermotor. Terhadap lingkungan udara dalam ruangan, gas $\mathrm{CO}$ dapat pula merupakan gas yang menyebabkan building associated illnesses, dengan keluhan berupa nyeri kepala, mual, dan muntah ${ }^{7}$.

Karbon monoksida $(C O)$ adalah gas yang tidak berwarna, tidak berbau, mudah terbakar dan sangat beracun. Merupakan hasil utama pembakaran karbo monoksida dan senyawa yang mengandung karbon monoksida yang tidak lengkap. ${ }^{3}$

Agar kadar emisi gas buang $\mathrm{CO}$ yang keluar dari knalpot dapat memenuhi standart baku mutu, maka perlu dilakukan upaya pengendalian antara lain dengan modifikasi mesin pembakar, pengembangan reaktor sistem pembuangan gas buang sehingga subtitusi bahan bakar untuk bensin menghasilkan polutan dengan konsentrasi rendah selama pembakaran, yaitu melakukan inovasi pada knalpot dengan penambahan glass wool, arang aktif, air atau bahan-bahan lain yang bersifat adsorben atau absorben. ${ }^{4}$

Arang aktif adalah arang yang telah mengalami perubahan sifat-sifat fisika dan kimianya karena dilakukan perlakuan aktifasi dengan aktifator bahan-bahan kimia ataupun dengan pemanasan pada temperatur tinggi, sehingga daya serap dan luas permukaan partikel serta kemampuan arang tersebut akan menjadi lebih tinggi. ${ }^{5}$

Ambang batas emisi gas buang karbon monoksida (CO), menurut Keputusan Gubernur DIY No. 167 Tahun 2003 tentang Ambang Batas Baku Mutu Emisi Sumber Bergerak, disebutkan bahwa ambang batas baku mutu emisi gas buang kendaraan bermotor khususnya sepeda motor untuk emisi gas buang karbon monoksida (CO) adalah sebesar 4,5 persen.

Tujuan penelitian ini Untuk mengetahui penurunan kadar emisi gas buang karbon monoksida $(\mathrm{CO})$ dengan penambahan arang aktif pada kendaraan bermotor.

\section{METODE PENELITIAN}

Jenis penelitian ini menggunakan metode deskriptif dan analitik. Desain (rancangan) penelitian yang digunakan Eksperimen dengan one group pre and post desigen.Lokasi penelitian di Balai Lingkungan Hidup (BLH) JL. Tentara Rakyat Mataram No. 53 Yogyakarta. Populasi dalam penelitian ini adalah emisi gas buang karbon monoksida (CO) pada knalpot motor honda supra.

Sampel pada penelitian ini adalah sebagian dari emisi gas buang karbon monoksida $(C O)$ yang tinggi yang keluar dari knalpot sepeda motor honda supra dan terdeteksi oleh alat Auto Check 974/S. 


\section{HASIL PENELITIAN DAN PEMBAHASAN}

\section{a. Hasil Penelitian}

Hasil Penelitian Pre dan Post test, Selisih, Penurunan Kadar Emisi Gas Buang Karbon Monoksida (CO) dengan Penambahan Arang Aktif Sebesar 50 gram Pada Kendaraan Motor Honda di Balai Lingkungan Hidup Yogyakarta 2009. Rata rata konsentrasi kadar emisi gas buang karbon monoksida (CO) sebelum penambahan sebesar 5,49 persen, sedangkan setelah diadakan penambahan dengan arang aktif diperoleh hasil rata - rata sebesar 5,35 persen. Dengan demikian terjadi penurunan rata - rata sebesar 0,14 persen atau dengan prosentase penurunan rata - rata sebesar 2,57 persen, jika dibandingkan dengan Keputusan Gubernur Daerah Istimewa Yogyakarta tentang standard baku mutu sumber bergerak kendaraan bermotor yaitu 4,5 persen berarti emisi masih berada diatas standard baku mutu yaitu 5,35 persen.

Hasil Penelitian Pre dan Post test, Selisih, Penurunan Kadar Emisi Gas Buang Karbon Monoksida (CO) dengan Penambahan Arang Aktif Sebesar 100 gram Pada Kendaraan Motor Honda di Balai Lingkungan Hidup Yogyakarta 2009. Rata - rata konsentrasi kadar emisi gas buang karbon monoksida (CO) sebelum penambahan sebesar 5,49 persen, sedangkan setelah diadakan penambahan dengan arang aktif diperoleh hasil rata - rata sebesar 4,33 persen. Dengan demikian terjadi penurunan rata - rata sebesar 1,16 persen atau dengan prosentase penurunan rata - rata sebesar 21,29 persen, jika dibandingkan dengan Keputusan Gubernur Daerah Istimewa Yogyakarta tentang standard baku mutu sumber bergerak kendaraan bermotor yaitu 4,5 persen berarti emisi sudah memenuhi atau dibawah standard baku mutu yaitu 4,33 persen.

Hasil Penelitian Pre dan Post test, Selisih, Penurunan Kadar Emisi Gas Buang Karbon Monoksida (CO) dengan Penambahan Arang Aktif Sebesar 150 gram Pada Kendaraan Motor Honda di Balai Lingkungan Hidup Yogyakarta 2009. Rata - rata konsentrasi kadar emisi gas buang karbon monoksida (CO) sebelum penambahan sebesar 5,49 persen, sedangkan setelah diadakan penambahan dengan arang aktif diperoleh hasil rata - rata sebesar 3,00 persen. Dengan demikian terjadi penurunan rata - rata sebesar 2,49 persen atau dengan prosentase penurunan rata - rata sebesar 45,68 persen, jika dibandingkan dengan Keputusan Gubernur Daerah Istimewa Yogyakarta tentang standard baku mutu sumber bergerak kendaraan bermotor yaitu 4,5 persen berarti emisi sudah memenuhi atau dibawah standard baku mutu yaitu 3,00 persen. Hasil Analisis One Way Annova

Tabel 7. Analisis uji Annova Penurunan Kadar Emisi Gas Buang Karbon Monoksida (CO) dengan Penambahan Arang Aktif 50, 100, 150 gram Pada Kendaraan Bermotor di Balai Lingkungan Hidup Yogyakarta 2009.

\begin{tabular}{lccccc}
\hline & Sum of Squares & $d f$ & Mean Square & $F$ & Sig. \\
\cline { 1 - 4 } Between Groups & 6.956 & 2 & 3.478 & & \\
\cline { 1 - 4 } Within Groups & 26.693 & 27 & .518 & .989 & \\
\cline { 1 - 4 } Total & 33.650 & 29 & & & \\
\hline
\end{tabular}

Berdasarkan hasil uji analisis statistik dengan uji One Way Annova (anava satu jalan) pada taraf signifikan á $=0,05$ didapatkan $p$ value untuk kadar karbon monoksida $(\mathrm{CO})$ sebesar $=0,044$ sehingga $p$ value $<$ á $=0,05$, maka disimpulkan bahwa ada perbedaan rata - rata penurunan kadar emisi gas karbon monoksida (CO) dengan penambahan arang aktif dengan kadar 50 gram, 100 gram, 150 gram pada kendaraan bermotor. 
Tabel 8. Analisis uji Annova Penurunan Kadar Emisi Gas Buang Karbon Monoksida (CO) dengan Penambahan Arang Aktif 50, 100, 150 gram Pada Kendaraan Bermotor di Balai Lingkungan Hidup Yogyakarta 2009

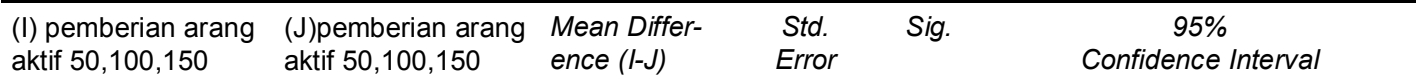
aktif $50,100,150$ gram gram

\begin{tabular}{ccccccc}
\hline \multirow{2}{*}{50 gram } & 100 gram & .50900 & .44466 & .496 & -.5935 & 1.6115 \\
\cline { 2 - 7 } & 150 gram & $1.17600^{*}$ & .44466 & .035 & .0735 & 2.2785 \\
\hline \multirow{2}{*}{100 gram } & 50 gram & -.50900 & .44466 & .496 & -1.6115 & .5935 \\
\cline { 2 - 7 } & 150 gram & .66700 & .44466 & .307 & -.4355 & 1.7695 \\
\hline \multirow{2}{*}{150 gram } & 50 gram & $-1.17600^{*}$ & .44466 & .035 & -2.2785 & -.0735 \\
\cline { 2 - 7 } & 100 gram & -.66700 & .44466 & .307 & -1.7695 & .4355 \\
\hline
\end{tabular}

Nilai mean difference rata - rata kadar 50gr terhadap kadar $100 \mathrm{gr}$ menunjukkan angka 0,509 berarti pemberian arang aktif $100 \mathrm{gr}$ lebih baik dari pemberian 50gr. Untuk nilai 95\% Confidence Interval berkisar antara - 0,5935 sampai 1,6115. Dilihat dari nilai signifikan untuk baris pertama nilai sig nya $0,496>$ 0,05 berarti tidak signifikan. Artinya kadar pemberian arang aktif $50 \mathrm{gr}$ dengan $100 \mathrm{gr}$ tidak ada perbedaan penurunan secara signifikan.

Nilai mean difference rata - rata kadar 50gr terhadap kadar $150 \mathrm{gr}$ menunjukkan angka $1.17600^{*}$ berarti pemberian arang aktif $150 \mathrm{gr}$ lebih baik dari pemberian $50 \mathrm{gr}$. Untuk nilai $95 \%$ Confidence Interval berkisar antara 0,0735 sampai 2.2785. Dilihat dari nilai signifikan untuk baris kedua nilai sig nya $0,035<0,05$ berarti signifikan. Artinya kadar pemberian arang aktif $50 \mathrm{gr}$ dengan $150 \mathrm{gr}$ ada perbedaan penurunan secara signifikan.

Nilai mean difference rata - rata kadar $100 \mathrm{gr}$ terhadap kadar $50 \mathrm{gr}$ menunjukkan angka -.50900 berarti pemberian arang aktif $100 \mathrm{gr}$ lebih baik dari pemberian 50gr. Untuk nilai 95\% Confidence Interval berkisar antara -1.6115 sampai 0,5935 . Dilihat dari nilai signifikan untuk baris ketiga nilai sig nya $0,496>$ 0,05 berarti tidak signifikan. Artinya kadar pemberian arang aktif $100 \mathrm{gr}$ dengan $50 \mathrm{gr}$ tidak ada perbedaan penurunan secara signifikan.

Nilai mean difference rata - rata kadar $100 \mathrm{gr}$ terhadap kadar $150 \mathrm{gr}$ menunjukkan angka 0,6670 berarti pemberian arang aktif $150 \mathrm{gr}$ lebih baik dari pemberian 100gr. Untuk nilai 95\% Confidence Interval berkisar antara -0,4355 sampai 1.7695. Dilihat dari nilai signifikan untuk baris keempat nilai sig nya $0,307>$ 0,05 berarti tidak signifikan. Artinya kadar pemberian arang aktif $100 \mathrm{gr}$ dengan $150 \mathrm{gr}$ tidak ada perbedaan penurunan secara signifikan.

Nilai mean difference rata - rata kadar $150 \mathrm{gr}$ terhadap kadar $50 \mathrm{gr}$ menunjukkan angka $-1.17600^{*}$ berarti pemberian arang aktif $150 \mathrm{gr}$ lebih baik dari pemberian 50gr. Untuk nilai 95\% Confidence Interval berkisar antara -2.2785 sampai $-0,0735$. Dilihat dari nilai signifikan untuk baris kelima nilai sig nya $0,035<$ 0,05 berarti signifikan. Artinya kadar pemberian arang aktif $50 \mathrm{gr}$ dengan $150 \mathrm{gr}$ ada perbedaan penurunan secara signifikan.

Nilai mean difference rata - rata kadar $150 \mathrm{gr}$ terhadap kadar $100 \mathrm{gr}$ menunjukkan angka $-0,6670$ berarti pemberian arang aktif $150 \mathrm{gr}$ lebih baik dari pemberian 50gr. Untuk nilai 95\% Confidence Interval berkisar antara -1.7695 sampai 0,4355 . Dilihat dari nilai signifikan untuk baris keenam nilai sig nya $0,307>$ 0,05 berarti tidak signifikan. Artinya kadar pemberian arang aktif $150 \mathrm{gr}$ dengan $100 \mathrm{gr}$ tidak ada perbedaan penurunan secara signifikan. 


\section{b. Pembahasan}

Berdasarkan hasil penelitian dan setelah dilakukan pengujian secara deskriptif maupun analitik dapat diketahui bahwa ada penurunan kadar emisi gas karbon monoksida dengan penambahan arang aktif pada kendaraan bermotor. Dari penambahan arang aktif 50 gram, 100 gram, 150 gram yang paling efektif untuk menurunkan kadar emisi gas karbon monoksida (CO) adalah 150 gram, jadi semakin banyak arang aktif maka akan terjadi penurunan gas karbon monoksida (CO) pada knalpot motor.

Obyek pada penelitian ini adalah emisi gas karbon monoksida pada mesin kendaraan motor honda supra 100 cc tahun 1997/1998. Pemeliharaan mesin ini memang sangat kurang dan tidak pernah dipanaskan secara berkala, kilometer mencapai 9.256.5, penggantian oli tidak teratur, dan jarang di service. Pemeliharaan mesin memang memegang peranan sangat penting dalam menekan tingkat polusi yang dihasilkan suatu kendaraan. Hal ini terjadi karena mesinlah yang merupakan sumber pencemar. Kondisi mesin atau bagian -bagian mesin yang tidak terpakai dalam waktu yang lama dapat menyebabkan beberapa komponen mesin menjadi tidak berfungsi dengan baik dan ini dapat mempengaruhi proses dari kerja mesin saat dihidupkan. Dalam pemeliharaan mesin hal - hal yang perlu diperhatikan untuk mengurangi polusi antara lain pemeliharaan mesin secara rutin dan pemeliharaan perangkat bahan bakar, selain itu dapat juga dengan inovasi teknologi seperti penambahan adsorben lain pada knalpot.

Pemeliharaan mesin yang perlu dilakukan secara rutin antara lain seperti penggantian oli sekitar setiap $2000 \mathrm{~km}$, busi, platina dan kondensator. Penggantian oli sebagai pelumas sangat penting bila kekentalan tidak memenuhi syarat maka akan terjadi kebocoran kompresi. Kandungan $\mathrm{CO}$ pada gas buang menjadi tinggi, terjadi penurunan tenaga, dan mesin cepat panas dan aus.

Karbon monoksida di lingkungan dapat terbentuk secara alamiah, tetapi sumber utamanya adalah dari kegiatan manusia, Karbon monoksida yang berasal dari alam termasuk dari lautan, oksidasi metal di atmosfir, pegunungan, kebakaran hutan dan badai listrik alam. Sumber CO buatan antara lain kendaraan bermotor, terutama yang menggunakan bahan bakar bensin.

Berdasarkan estimasi, jumlah $\mathrm{CO}$ dari sumber buatan diperkirakan mendekati 60 juta ton per tahun. Separuh dari jumlah ini berasal dari kendaraan bermotor yang menggunakan bakan bakar bensin dan sepertiganya berasal dari sumber tidak bergerak seperti pembakaran batu bara dan minyak dari industri dan pembakaran sampah domestik. Didalam laporan WHO (1992) dinyatakan paling tidak $90 \%$ dari CO diudara perkotaan berasal dari emisi kendaraan bermotor. Selain itu asap rokok juga mengandung $\mathrm{CO}$, sehingga para perokok dapat memajan dirinya sendiri dari asap rokok yang sedang dihisapnya.

Pemajanan CO dari udara ambien dapat direfleksikan dalam bentuk kadar karboksi-haemoglobin $(\mathrm{HbCO})$ dalam darah yang terbentuk dengan sangat pelahan karena butuh waktu 4-12 jam untuk tercapainya keseimbangan antara kadar CO diudara dan $\mathrm{HbCO}$ dalam darah Oleh karena itu kadar $\mathrm{CO}$ didalam lingkungan, cenderung dinyatakan sebagai kadar rata-rata dalam 8 jam pemajanan, data CO yang dinyatakan dalam rata-rata setiap 8 jam pengukuran sepajang hari (moving 8 hour average concentration) adalah lebih baik dibandingkan dari data $\mathrm{CO}$ yang dinyatakan dalam rata-rata dari 3 kali pengukuran pada periode waktu 8 jam yang berbeda dalam sehari.

Pencemaran udara berdasarkan pengaruhnya terhadap gangguan kesehatan dibedakan menjadi 3 jenis yaitu: 
1) Irintasi : Biasanya polutan ini bersifat korosif. Merangsang proses peradangan hanya pada saluran pernapasan bagian atas, yaitu saluran pernapasan mulai dari hidung hingga tenggorokkan. Misalnya Sulfur Dioksida, Sulfur Trioksida, Amoniak, debu. Iritasi terjadi pada saluran pernapasan bagian atas dan juga dapat mengenai paru-paru sendiri.

2) Asfixia: Disebabkan oleh ber-kurangnya kemampuan tubuh dalam menangkap oksigen atau mengakibatkan kadar $\mathrm{O}_{2}$ menjadi berkurang. Keracunan gas Karbon Monoksida mengakibatkan $\mathrm{CO}$ akan mengikat hemoglobin sehingga kemampuan hemoglobin mengikat $\mathrm{O}_{2}$ berkurang terjadilah Asfiksia. Yang termasuk golongan ini adalah gas Nitrogen, Oksida, Metan, Gas Hidrogen dan Helium.

3) Anestesia : Bersifat menekan susunan syaraf pusat sehingga kehilangan kesadaran, misalnya aeter, aetilene, propane dan alkohol alifatis.

Pencegahan terjadinya pecemaran gas karbon monoksida pada sumber emisi bergerak:

1) Merawat mesin kendaraan bermotor agar tetap baik.

2) Melakukan pengujian emisi dan KIR kendaraan secara berkala dan memasang filter pada knalpot.

Adsorbsi dalam arang aktif terjadi secara fisik, proses adsorbsi terjadi karena sifat yang dimiliki arang aktif sebagai penyerap, penyaring molekul, katalis dan penukar ion. Arang aktif merupakan adsorben yang memiliki pori - pori diameter yang sangat kecil yang dapat menyerap gas, sehingga gas $\mathrm{CO}$ yang melewatinya akan terikat dan mengalami gaya tarik menarik dengan pori - pori arang aktif.

Pada penelitian ini arang aktif yang sudah diaktifkan dan siap dipakai, dengan variasi 50 gram, 100 gram, 150 gram yang dibungkus dengan kawat kasa menjadi dua bungkus yang diletakkan diruang antara pipa buang difuser dan ruang antara pipa pemancar sehingga berbentuk seperti huruf $U$. Maksud dari pembungkusan ini adalah agar arang aktif tidak berhamburan keluar knalpot pada saat mesin dinyalakan. Banyaknya arang aktif pada bungkusan pertama sebesar 20 gr yang diletakkan pada ruang antara pipa difuser dan $30 \mathrm{gr}$ diletakkan pada ruang antara pipa pemancar, dan bungkusan kedua sebesar $40 \mathrm{gr}$ yang diletakkan pada ruang antara pipa difuser dan $60 \mathrm{gr}$ diletakkan pada ruang antara pipa pemancar, dan bungkusan ketiga sebesar $70 \mathrm{gr}$ yang diletakkan pada ruang antara pipa difuser dan $80 \mathrm{gr}$ diletakkan pada ruang antara pipa pemancar.

Setiap kali pengulangan dilakukan penggantian media arang aktif yang baru, sehingga tidak jenuh dan tercipta kondisi yang sama setiap kali pengukuran. Dengan demikian pengaruh dari penambahan arang aktif terhadap kadar emisi gas karbon monoksida pada kendaraan bermotor benar - benar dapat diketahui dengan didapatkan data yang aktual.

Banyaknya arang aktif yang digunakan dalam penelitian ini belum disesuaikan dengan jumlah emisi yang dikeluarkan suatu kendaraan bermotor, artinya belum ada standart yang tepat mengenai kebutuhan arang aktif agar seimbang dengan emisi yang dikeluarkan dan arang aktif dapat secara maksimal mengikat emisi karbon monoksida (CO) yang keluar dari knalpot kendaraan motor. Banyaknya arang aktif pada penelitian ini hanya disesuaikan dengan daya tampung dari ruang knalpot yang ditambah arang aktif, penelitian ini belum pernah dilakukan pengukuran kadar emisi gas buang karbon monoksida dengan variasi waktu, artinya pada penelitian ini hanya dilakukan pengambilan sampel beberapa kali setelah penggantian arang aktif sehingga tidak dapat diketahui waktu jenuh dari arang aktif tersebut. 


\section{SIMPULAN DAN SARAN}

\section{a. Simpulan}

Ada penurunan kadar emisi gas buang karbon monoksida (CO) dengan penambahan arang aktif pada kendaraan bermotor, yaitu dengan variasi 50 gram rata - rata selisih sebesar 0,14 persen atau dengan prosentase penurunan sebesar 2,57 persen, yaitu dari kadar 5,49 persen menjadi 5,35 persen. variasi 100 gram rata - rata selisih sebesar 1,16 persen atau dengan prosentase penurunan sebesar 21,29 persen, yaitu dari kadar 5,49 persen menjadi 4,33 persen dengan variasi 150 gram rata - rata selisih sebesar 2,49 persen atau dengan prosentase penurunan sebesar 45,68 persen yaitu dari kadar 5,49 persen menjadi 3,00 persen.

\section{b. Saran}

Berdasarkan hasil penelitian dan pembahasan, maka dapat diberikan saran kepada :

1) Bagi Konsumen Kendaraan Bermotor

Agar sering melakukan pemeriksaan mesin pada kendaraan bermotor atau service di bengkel kendaraan motor agar tidak terciptanya polusi karbon monoksida $(\mathrm{CO})$ pada udara yang tinggi.

2) Bagi Peneliti Lainnya

Diharapakan dapat membandingkan pengukuran variasi jumlah arang aktif sehingga dapat ditentukan jumlah bahan adsorben yang tepat untuk menurunkan kadar emisi gas buang karbon monoksida secara optimal dan dapat meneliti dengan variasi waktu agar dapat ditentukan efiktifitas arang aktifnya.

\section{KEPUSTAKAAN}

1. Budiraharjo, H., Pencemaran Udara di DKI Jakarta Paru, Jakarta. 1991

2. Wardhana, S., Dampak Pencemaran Lingkungan, Yogyakarta. 2001

3. Handayani, L., Gas Karbon Monoksida (CO) dan Dampaknya Terhadap Kesehatan, pelajaran kuliah pencemaran gas karbon monoksida (CO), Universitas Ahmad Dahlan Yogyakarta. 2008.

4. Daryanto. Masalah Pencemaran. Transito. Bandung.1995

5. Sembiring, M.T., Arang Aktif (Pengenalan dan Proses Pembuatannya), Jurusan Teknik Industri Fakultas Teknik Universitas Sumatera Utara : www. Google.com, diambil pada tanggal 22 Maret 2009, Yogyakarta.2003

6. Tugaswati,A,T. ,Emisi Gas Buang Kendaraan Bermotor dan Dampaknya Terhadap Kesehatan, Jurnal Automotive Air Pollution in Jakarta with Special emphasis on lead, Particulate, and nitrogen dioxide. Jpn J of Health and human Ecology, 61:261-75 .1995

7. Anonim. Dampak B3 Terhadap Kesehatan. Www.Kesmas.tk/2009/11/dampak-b3terhadap-kesehatan.html-89k- 
